\title{
Educational heterotopia and students' use of Facebook
}

\author{
Andrew Hope \\ School of Social Sciences, University of Adelaide
}

\begin{abstract}
Facebook use in higher education has grown exponentially in recent years, with both academics and students seeking to use it to support learning processes. Noting that research into educational cyberspace has generally ignored spatial elements, this paper redresses this deficiency through using Foucault's (1986) discussion of different spaces to examine Facebook use. Recognising that more than simple façade space is also social practice, Foucault's heterotopian principles are used to explore spatial notions of difference (deviance and divergence), relational aspects (conflicts and connections) and flow (time and thresholds). It is argued that social networking sites offer possibilities for creative deviations, can foster learning communities and help to develop social relations. Yet they also distract students, allowing them to escape seminars, whilst giving rise to damaging, rigid definitions of work and study. Ultimately, if universities are to be architects of the future, rather than its victims, the inherent differences of such learning spaces need to be recognised and traditional notions of academic work challenged.
\end{abstract}

\section{Introduction}

As Facebook use in higher education institutions has grown rapidly, so has research analysing its uses to facilitate both formal and non-formal learning. Whilst this body of research offers rich insights into how students and staff (mis)use this technology, it largely ignores spatial dynamics. Significantly space is more than mere surface; it is a social construct, given meaning through social practices (Kozlovsky, 2010). Consequently it should not be seen as a supplementary consideration in the examination of educational practices, but deeply intertwined with such processes. Moreover, as Gulson and Symes (2007; p. 98) argue:

[E]xamining educational policy from a spatial perspective is not about creating new problems as such, but rather it is about providing explanatory frameworks that, perhaps, disrupt understandings in, and posit new possibilities for, both mainstream and critical educational studies.

Adopting a spatial focus, this paper uses Foucault's (1986) notion of heterotopia to examine Facebook use in higher education. Drawing upon semi-structured interviews with 10 first year undergraduate students, issues relating to difference (deviance and divergence), relational aspects (conflicts and connections) and flow (time and thresholds) are explored. Whilst attention is drawn to problems such as the use of Facebook to escape seminars, the conflict between work/study space and the transitory, distracting nature of time online, it is also noted that new learning possibilities exist. Thus it is maintained that social networking sites can offer possibilities for creative deviations, foster learning communities and help to develop broader social skills. Yet such outcomes may only be achieved if educational social networking sites (SNS) use engages with difference, rather than simply seeking to replicate traditional learning and teaching approaches. Educational heterotopia could provide a useful, critical tool in this process.

Although Facebook is the primary focus of this paper, the generic term of SNS is also used, suggesting that the research findings have a broader application to other, similar websites. Before considering Foucault's notion of heterotopia and reflecting upon how this theoretical framework can be drawn upon to better understand SNS use, it will first be useful to consider research on the use of Facebook as a learning tool.

\section{Facebook - the educational network?}

Facebook is a social networking website that was initially designed for students at United States universities, which later spread to other educational institutions and beyond. It was reported that there were 1.49 billion Facebook monthly active users (MAUs) for June 2015 (Rosenfeld, 2015), although the 
company's own report suggests that between 5.5\% and $11.2 \%$ of all accounts on Facebook are malicious, duplicate or otherwise fake (Facebook, 2014). It is claimed that the majority of undergraduate students in higher education use Facebook on a daily basis (Kirschner \& Karpinski, 2010; Roblyer, McDaniel, Webb, Herman, \& Witty, 2010). Indeed it is argued that Facebook use in educational institutions should be seen as a normal extension of students existing use of social media networks in their private lives (Staines \& Lauchs, 2013). Moreover, although primarily a social tool, Facebook is also increasingly being recognised as a reputable learning technology (Bosch, 2009). Consequently, there is a burgeoning body of research on Facebook use in higher education focusing upon its application as a learning tool as well as its broader social dynamics.

Social networking applications share some of the highly sought after qualities of effective education technologies and learning practices that have been formally adopted by schools and universities (Mason, 2006), including reflective practice, peer feedback and collaborative models of learning. Since these technologies were not typically designed for educational purposes, however, the manner in which they are appropriated and utilised can influence the potential benefits for learning and teaching (Hamid, Waycott, Kurnia, \& Chang, 2014). While some academics have sought to use Facebook in their course as part of formal learning experience, with associated learning outcomes, clearly defined curriculum content, related assessment and guidance from tutors, others have utilised it in a more ad hoc manner. Indeed much of the informal learning that occurs via Facebook arises from students' own initiatives, through self-directed study, incidental knowledge acquisition or the broader processes of socialisation. Consequently few see education through social networking sites as a replacement for more formal teaching instruments. Rather, it is argued that such websites should be seen as supplementary learning tools, providing additional learning opportunities or enhancing participation (Hung \& Yuen, 2010). This also reflects mixed responses regarding the perceived effectiveness of using Facebook to aid specific learning (Irwin, Ball, Desbrow, \& Leveritt, 2012) and student reluctance to use social networking sites for formal teaching purposes (Madge, Meek, Wellens, \& Hooley, 2009). Thus Vivian (2011; p. 258) found that "students were definitely using FB for informal learning; to discuss coursework, assignments, revise, share information and provide support”. Bosch (2009) also draws attention to the administrative use of Facebook at university, as a conduit for dealing with student queries, whilst allowing them to indicate the curriculum areas in which they want more guidance.

Underpinning much of the discussion of the educational potential of Facebook is the awareness that it is first and foremost a social networking tool. Thus Madge et al. (2009) maintain that Facebook provides a social glue to assist students settling into university life. Indeed Selwyn (2009) found that students used Facebook to reflect on their university experience, exchange practical as well as academic information, display disgruntlement and partake in exchanges of humour or nonsense. He concluded that social network use should be seen as part of identity politics, as "Facebook has become an important site for the informal, cultural learning of being a student, with online interactions and experiences allowing roles to be learnt, values understood and identities shaped” (Selwyn, 2009; p. 171).

While some educators are enthusiastic about possible uses of social networking sites, stressing their potential to enhance student engagement, improve communication and foster flexibility within courses, others remain wary. Aydin (2012; p. 1101) suggests that there might be harmful repercussions of Facebook use including "inappropriate behavior, abuse, cyberbullying, and invasions of privacy". Furthermore, there is concern that social network use might impinge on more formal learning activities, such as preparing for seminars, with consequent negative effects on academic performance (Junco, 2012; Kirschner \& Karpinski, 2010). It is also suggested that such technologies might be intellectually disempowering. Hence, McRae (2014; p. 30) warns that:

[T]he fundamental experiences of learning - struggle with ideas, disciplining the mind, exploring concepts with individuals more expert than the student - is impoverished as we offload students onto social networks and out of classrooms.

Despite a growing body of research there is still much uncertainty regarding if and how Facebook use in universities can enhance student learning outcomes (Irwin et al., 2012). Some of this doubt reflects the vastly differing ways in which markedly different groups use SNS. After all, as Leaver and Kent (2014; p. 61) note: 
Facebook is not a singular tool, but a wide-ranging set of tools and practices tied together in an online platform. Different uses of this platform will inevitably lead to different outcomes, including different outcomes in terms of informal and formal education.

Moreover, student Facebook use should not be viewed in isolation, but rather as forming part of a communicative assemblage that includes mobile digital devices, other software applications and traditional face-to-face modes of interaction (Selwyn, 2009). Ultimately, there is something in the nature of social networking sites that obfuscates assessment of their use as learning and teaching tools. This might reflect that such websites could be viewed as different spaces.

Discussions of space are often absent from research into Facebook use. Yet, part of the rationale for using Facebook in education is to meet students in their online spaces (Stutzman, 2008). Moreover, social networking sites were seen as a way of encouraging students to interact in spaces beyond lecture halls and seminar rooms (Hung \& Yuen, 2010). Clearly space plays a key role in these online learning processes; nonetheless it is often ignored. In seeking to address this deficiency it is first necessary to consider the social-cultural conceptualisation of space. The focus will then shift to Foucault's notion of heterotopia and how this may engender a more critical understanding of these educational cyberspaces.

\section{Heterotopia and educational cyberspace}

Although the notion of space that emerged in nineteenth century architectural criticism signified only the volumetric properties of a building, since the 1980s it has been increasingly recognised that "this concept is also understood as a social practice, as a site for the study of power relations and the production of the self” (Kozlovsky, 2010; p. 696). Thus space is more than mere surface; it is a product of ongoing social processes (Massey, 1999). Hence Gulson and Symes (2007; p. 105) note that educational space is "fluid and ephemeral ... being re-written and re-inscribed, formed and deformed as each pedagogic moment is transformed into another and as they are acted out in time”. Social networking sites are different from the educational norm. Clearly cyberspace differs from physical space, yet the two are connected through the notion of space as social practice. Thus any critical analysis of Facebook as a learning space needs to adopt a nuanced approach, focusing on the spaces (re)created through social practice. Ultimately this will allow a deeper understanding of educational (non)use of SNS as well as revealing new issues that need to be addressed if learning is to prosper. Foucault's conceptualisation of heterotopia offers an innovatory theoretical framework.

French social historian, Michel Foucault's, (1986) exploration of heterotopian spaces has generated many interpretations and applications across numerous disciplines, including architecture, geography, sociology and education. Although the term heterotopia has it origins in medicine, where it refers to the presence of tissue in an abnormal body location, Foucault uses it to suggest new ways of thinking about novel and unorthodox spaces. Thus he suggests that heterotopias are counter-sites; different spaces, which mirror aspects of everyday life whilst simultaneously distorting, contesting or inverting (Foucault, 1986). Key to understanding Foucault's notion of heterotopia are six governing principles, which he argues feature to varying degrees in these different spaces. Foucault illustrates each of his principles with examples of specific sites; however, some of these discussions are severely underdeveloped and the list is "almost mischievous in its variety” (Johnson, 2013; p. 790).

Firstly, heterotopias take varied forms, although it is possible to distinguish two main categories. Crisis heterotopias (relating to such things as adolescence, menstruation, pregnancy and the elderly) are steadily being replaced by heterotopias of deviation, where behaviour differs from the norm. In this latter grouping Foucault offers the somewhat jarring examples of rest homes, psychiatric hospitals and prisons. Secondly, discussing the development of cemeteries, Foucault asserts that heterotopias may function in different ways with their use being refashioned over time. Thirdly, "heterotopia is capable of juxtaposing in a single real place several spaces, several sites that are themselves incompatible” (Foucault, 1986; p. 12), such as in the theatre or an ornamental garden. Fourthly, heterotopias are linked to slices of time offering a kind of absolute break with traditional time, either through accumulating time (e.g. museums and libraries) or being transitory, flowing and precarious (e.g. fairgrounds and exotic holiday villages). Fifthly, heterotopias encompass a system of opening and closing that isolates them as well as making them penetrable. The examples offered here include Muslim hammins, Scandinavian saunas and American motel rooms. Finally, heterotopias "have a function in relation to all space that remains" 
(Foucault 1986; p. 16), which lies somewhere between illusion (found, he claims, in grand French brothels) and the compensation offered by perfection (to be discovered in puritan colonies).

Foucault's work in this area is not without its limitations. His accounts of heterotopia are recognised as ambiguous, playful and sketchy. Indeed, he discusses the concept on only three occasions, that is in a book preface (Foucault, 1970), a 12 minute radio interview and a 1967 lecture to architects (Foucault, 1986). The lecture, which is Foucault's most protracted consideration of heterotopia, is upon occasion as confounding as it is dazzling, suggesting that different spaces mirror, reflect, designate, represent and speak about, whilst also neutralising, contradicting, contesting, inverting and suspending (Johnson, 2006). Avoiding critical consideration of the exemplar sites somewhat playfully suggested by Foucault, these principles nevertheless offer a creative way to explore how students use social networking sites to facilitate their learning.

Educational researchers have used heterotopia to explore a range of spatial issues including gendered places (Ingrey, 2013), women's colleges (Tamaboukou, 2004), further education establishments (Blair, 2009) and the business university (Beyes \& Michels, 2011). The concept has also been more extensively used in the study of online spaces, examining the nature of cyberspace (Cohen, 2007; Young, 1998), email discussion lists (Warschauer, 1995), online encyclopaedias (Haider \& Sundin, 2010), teleconferencing (Krikonis \& Valsiner, 2008), MOOCs (Willis, Spiers, \& Gettings, 2013) and Facebook (Rymarczuk \& Derksen, 2014). Echoing Genocchio (1995; p. 36) it can be asserted that studies adopting this theoretical framework often provide little sustained critical engagement with Foucault's text, rather “calling up heterotopia as some theoretical deus ex machina”. Nevertheless, some of the research avoids this pitfall, while suggesting interesting lines of thought that warrant closer scrutiny.

Exploring student participation in university online learning communities Ferreday and Hodgson (2010) stress the disturbing aspects of different spaces that draw people out of themselves, produce disruptions and form a reservoir of imagination that facilitate critical reflection and learning opportunities. Thus deviation from more traditional modes of teaching and learning, may offer new creative spaces. Ferreday and Hodgson (2010) also describe how over time such digital spaces allowed for changes, notably a reappropriation of the social. Students started to post non-academic messages in a catching up discussion theme, illustrating both deviations from the academic tone of the online work and emerging differences as the nature of these online spaces changed. Linking Foucault's first and second principles of heterotopia, it can be suggested that social networked learning "spaces refuse the tyranny of the search for utopianism: instead they allow for deviation and difference” (Ferreday \& Hodgson, 2010; p. 9). Subsequently, rejecting an idealised version of SNS based learning encourages an exploration of the potential educational gains arising from difference online, as embodied in practices fostering deviation and divergence.

Educational cyberspace should not be thought of as homogenous. Rather it is amorphous and diverse. Hence as Young (1998, para 14) notes "not only can cyberspace as a whole be considered a heterotopia but within cyberspace itself there must exist heterotopias”. Such a viewpoint raises questions about the relations between online spaces (heterotopian or otherwise), particularly the contrasts and connections that might exist. Heterotopian cyberspaces may juxtapose sites that are in some way incompatible. Thus, Rymarczuk and Derksen (2014; p. 8) suggest that Facebook use contains conflicts as "the very distinction between public and private is rapidly becoming obsolete, and the boundaries between some of our everyday places (e.g., work space and social space) are being blurred”. Consequently, attempts to use Facebook to facilitate learning in higher education may be prone to clashes between work and social life. Although these different spaces may contain contradictory elements connections also exist; functions in relation to all remaining espace (Foucault, 1986). Willis et al., (2013; p. 8) assert that this relational aspect of heterotopia helps bridge the gap between individuals and learning communities, place and nonplace, as "MOOC students who are self-efficacious contribute to learning in a community; the very act of commitment to participatory learning lends relational development within the community". Connecting the third and sixth heterotopian principles, it can be seen that these contradictory spaces contain not only jarring juxtapositions, but also functional connections. Understanding these relational aspects is essential to fully realising the potential of networked learning.

Traditionally education has highly structured segmentation of time, embodied in the regimen of lectures, seminars, assignment deadlines and examination times. It is argued that cyberspace has somewhat blurred 
temporal boundaries, however. Similarly heterotopian slices of time offer a break with traditional temporal structures, through stressing the accumulation or transitory nature of time. Commonly the latter is expressed with reference to online activity that takes an inordinate amount of time, but is ultimately inefficient or unproductive. Thus it is recognised that Facebook use can distract students from their studies. As individuals are beguiled by the online spectacle not only does the moment become transitory, but possibly the intent to work. Whilst recognising this likelihood, Rymarczuk and Derksen (2014; p. 5) also maintain that Facebook accumulates time as "fragmented bits of personal information, supposedly reflecting a particular present moment, are uploaded to construct a kind of linearity" and through "facilitating and storing real-time conversation the platform creates a detailed log of a digital personal past”. Although this is a highly literal interpretation of accumulating time, it nevertheless draws attention to the surveillance capacity of such technology. Data appears onscreen representing temporally situated (in)actions, allowing students and teachers to explore their own and others apparent uses of time. Whilst the flow of time differs in heterotopias, so too does the flow of people. An opening/closing system makes these different spaces isolated as well as penetrable. Facebook is ostensibly free, but a user can only enter the space once they have identified themselves and registered. Other higher education based courses utilising online learning are likely to have even more stringent conditions for entry, such as formal enrolment, the payment of course fees and timely submission of assignments. Of course, more informal social pressures may operate to exclude learners in situations where they feel ostracised by their group. Associating Foucault's fourth and fifth heterotopian principles through the notion of flow, it can be seen that the flux of time and people can combine to impact on SNS learning experiences. Whilst this could result in reinforcing a sense of being and belonging, there is also the chance of such flows reinforcing the “dark side of participation” (Willis et al., 2013; p. 4), encouraging critical scrutiny of online (in)actions and raising the possibility of exclusion from the group.

While the unstable nature of Foucault's notion of heterotopia means certain wariness should be adopted when it is used, it nevertheless can offer insights into the broadly educational use of Facebook in higher education, through focusing attention on the transient and social nature of space, particularly with regard to difference (deviation and divergence), relational aspects (contradictions and connections) and flow (time and thresholds). Before further exploring these issues through narratives given by first year university students, it is necessary to describe the data gathering process.

\section{The research process}

The following data is drawn from research undertaken at a large urban university in the north of England. This institution gained its university status in 1992 through the Further and Higher Education Act (1992) and with a student population of around 35,000 is one of the largest universities in the country. The study examined first year undergraduate use of digital technologies as they started to engage with e-learning in the tertiary sector. This paper draws upon data from ten semi-structured interviews and one follow-up focus group interview. Whilst recognising the limitations of using such a small number of respondents, it is worth echoing Crouch and McKenzie's (2006) assertion that analytic, inductive, exploratory studies are perhaps best undertaken using small groups. In order to produce a diversity of categories and information students in three different age groupings (20 or under, 21-25 and 26-35), studying one of three degrees (Information and Communication, Spanish and TEFL or Sociology) were selected (see table 1). As the research project principally focused upon the so-called net generation no one over the age of 35 was included in the sample. Whilst the exclusion of older students might be seen as problematic, it had the benefit of focusing the research upon those age groups that constitute the majority of the undergraduate population. 
Table 1

Respondents

\begin{tabular}{llll}
\hline Name & Age & Sex & Degree studied \\
\hline Amrita & 20 or under & Female & Sociology \\
Brent & $21-25$ & Male & Information and communications \\
Cathy & $26-35$ & Female & Spanish and TEFL \\
Dylan & $26-35$ & Male & Information and communications \\
Ellen & 20 or under & Female & Information and communications \\
Franz & 20 or under & Male & Information and communications \\
Gerald & $21-25$ & Male & Sociology \\
Harriet & 20 or under & Female & Sociology \\
Isabella & 20 or under & Female & Sociology \\
Julie & 20 or under & Female & Sociology \\
\hline
\end{tabular}

Thematic analysis was used to examine the data, with writings on educational SNS use and the sociology of space helping to foreshadow emerging issues (Ryan \& Bernard, 2003). Themes were developed from categories identified in the data, which built on codes identified in the transcripts that related to the research focus. Themes emerged such as difference, (dis)connections and time which provided a basis for a theoretical understanding of the data that also resonated with writings on heterotopia.

Although the initial research focus was upon new students' wide-ranging use of digital technologies at university, the topic of Facebook usage emerged as a key issue. Educational research on Facebook use varies. Some studies seek to assess formal learning opportunities, underpinned by clearly defined outcomes, curriculum content and assessment exercises, while others are more concerned with informal learning, arising from self-directed study and the broader processes of socialisation. As none of the respondents were involved in using Facebook as a formal, prescribed learning tool, this study falls into the latter category. Whilst not wishing to dismiss the potential of Facebook as a formal learning tool, it should be recognised that the vast majority of university students do not currently use it in this manner. This suggests that exploring students' commonplace SNS use in their everyday lives is of paramount importance.

In exploring heterotopian elements of Facebook use the subsequent analysis tends to privilege the notion of space as practice, focusing particularly on activities in cyberspace. Yet it should be recognised that the simultaneous experience of physical, off-line space is also important. After all, the qualities of the offline spaces used will arguably impact on the students' broader experience of being online. Importantly the mobility afforded by digital devices such as tablets and smartphones can influence the choice of physical spaces in which students choose to access Facebook. Although it is recognised that mobile learning offers an important area for future research into educational spaces, this paper adopts a narrower research focus, concentrating on space as social practice within SNS. Discussion will now focus on three threads found in the research data namely difference, relational elements and flow. These will be considered in turn.

\section{Of different cyberspaces: Deviation and divergence}

It is noteworthy that Foucault's published lecture on heterotopia has given rise to three distinct English translations featuring two different titles, Of Other Spaces (Foucault, 1986, 2008) and Different Spaces (Foucault, 1998). It can be argued that with reference to an examination of educational cyberspace difference is a more useful concept than the jarring notion of the other. Logically, this raises the question of the extent of the difference and how it can be measured. In this regard Foucault's argument is not assisted by his use of various absolutist phrases suggesting that heterotopia is utterly different from all spaces (Johnson, 2013). Adopting a less extreme interpretation and referring back to Foucault's first and second principles of heterotopia it can be argued that the difference evident in Facebook use relates to deviations from the norm and changes over time.

Although Ferreday and Hodgson (2010) stressed the potential for SNS to disrupt more traditional modes of teaching and learning, spurring the imagination, it is notable that they initiated and monitored student use of educational cyberspace. It would appear that habitual student use of Facebook has a far less formal 
educational role to play. Thus interviewees described what could be labelled as a more mundane use of Facebook to facilitate their learning:

[W]e have a presentation coming up in a couple of weeks, and we've got our own sort of little Facebook community discussing that. Unfortunately we've not come up with any good ideas yet, but that's the way we communicate. It's not like we have major discussions on it, it's just sort of coming up with like times to meet, key points we wanna discuss. (Gerald)

Gerald's description of Facebook use, which was typical of other respondents' narratives, highlights a practical element. It also suggests that imaginative disruptions and deviations from normal ways of preparing group presentations do not necessarily occur in everyday educational SNS use. Consequently, it can be suggested that Ferreday and Hodgson's (2010) research describes the potential, rather than the commonplace.

Students identified ways in which Facebook facilitated deviant behaviour in higher education. Discussing seminars in which they were being trained to use a Statistical Package for the Social Sciences (SPSS) they related "that's what everybody does in my group, they're just on Facebook for the whole hour and we got it today at four o'clock and everyone will just be on Facebook” (Amrita). Thus Facebook offered a disruption from learning processes, as bored students tuned out the seminar and logged into social networking websites. Nevertheless, some students described using Facebook in such classes as a motivational reward rather than an avoidance tool, declaring that "I just follow the [seminar] instructions and then at the end I just sneak on Facebook for 10 minutes” (Gerald). Although such an incentive may motivate students to learn, more extensive Facebook use in seminars as a result of disengagement is likely to produce distracting deviations that limit students' educational gains in that particular setting. In short it allows student to exit the learning space.

Foucault (1986) notes that heterotopias function in different ways with their use being refashioned over time. In this context, educational cyberspaces can evolve and be (re)appropriated. It is often social aspects that are at the forefront of discussions about how Facebook can develop learning and teaching in higher education. Yet, social networking occurs online at University that has little identifiable educational outcome. Thus Facebook is used "mainly for talking and socialising really" (Julie), "to be the first to know who's released a new album" (Brent) and to "get to know each other. We kind of learnt who each other's favourite bands were and stuff and we all had some sort of common interest to talk about" (Gerald). What is particularly curious about Gerald's comment is that the Facebook group had been set up by the students to help with project work for a particular course. Yet, it was music and similar stuff, which was seen as providing common interest, not the academic work. This highlights that Facebook is foremost a social tool. Hence Ferreday and Hodgson (2010) describe how students feeling restricted by the formal online academic discourse developed an alternative online space to catch up.

\section{Relational online spaces: contrasts and connections}

Heterotopias embody a set of associations "with different degrees of relational intensity" they reflect and clash (Johnson, 2006; p. 87). Hence key to exploring different spaces is how they interact, providing juxtapositions and connections. Rymarczuk and Derksen (2014) suggest that Facebook use increasingly highlights divisions such as public/private and work/social life. Although no respondent raised the possibility that Facebook might blur boundaries between the public and the private, they did note that it created conflicts between work and leisure. Typically students remarked that since they used their computer for both work and social activity the possibility of distraction was high: "[A]ll my studies is [sic] on the computer as well so it's like difficult to try to type Google in and not type Facebook in so it can be a bit distracting” (Ellen). Yet they had no difficulty differentiating between what might constitute academic work as opposed to recreational play. Thus the juxtaposition of cyberspaces made the temptation to avoid work greater, but it didn't seemingly foster a categorical confusion in which they became unsure whether their activities counted as study. This may reflect that they had a stringent definition of what constituted academic work, often related to the completion of assignments. In this context, students commonly asserted that "if it [Facebook] wasn't there completely, then I'd do a lot more work” (Brent). Despite use of Facebook to facilitate educational processes, such as group meetings or sharing notes, it was still described as contrasting with work. Although courses that formally require 
Facebook use and contributions to discussion boards may mitigate against this perception, this does hint at underlying values.

Whilst Facebook has been characterised as the social network, students also expressed conflicting views that labelled SNS as unsocial and anti-social. It is unsurprising that such networking sites exhibit the complex, messy reality of everyday social interactions, yet it is worth considering the possible educational consequences that such aspects might have. Thus as one student remarked "when people leave status updates I think a lot of the time people just do it to get at people with stuff like I feel stabbed in the back today" and "I'll get messages off people that I have to pretend to like" (Gerald). Thus Gerald illustrates how there could be negative feelings associated with Facebook use, while the boundaries between friend/peer/enemy might blur. Indeed Ferreday and Hodgson (2010) draw attention to what they label as the shadow side of participation, wherein students ostracise members of their online learning groups. The ambiguity of online communication, allowing for greater misinterpretation, compared to face-to-face interaction, might make it more likely for such conflicts to occur. Moreover it was noted that Facebook had anti-social potential, with students who "don't go out as much, they just sit on YouTube or Facebook somebody who doesn't like to socialise basically” (Julie). Interestingly Julie appeared to disprivilege social networking websites as locations for real socialising. Whilst such juxtapositions might have an impact on student well-being and learning, the conflicts are perhaps not as extreme as those that Foucault describes in characterising heterotopian sites. This reflects that some spaces are more "fully functioning” or “highly heterotopian” (Foucault, 1986; p. 13).

Heterotopias not only juxtapose discordant elements, they also have a function in relation to remaining spaces. A common assertion of educational cyberspace use is that it allows beneficial symbiotic connections between the individual and learning communities (Ferreday \& Hodgson, 2010). Thus involvement in online participatory learning is seen as fostering the community while benefiting the individual, bridging educational gaps. None of the respondents were involved in SNS that had been formally established as part of course learning and teaching requirements. Yet students still used Facebook to collaborate as well as communicate:

I did some notes, my mate did some notes yeah, we just use it send to each other over Facebook we would, just post on each other pages or we have like a discussion board and we just, if we have a question or we're not going to come to a meeting we just put I won't be coming to the meeting and then the rest of the group can see it. (Ellen)

Thus, in addition to more mundane administrative tasks some students used Facebook to share notes and discuss questions. There was also a suggestion that occasionally students focused on more academic issues. As Gerald noted such discussions, which were often related to completing assignments such as group presentations, tended to fail to produce good ideas or be particularly major. Yet, even limited online academic discussions are noteworthy given that these arose from students' own impulses, albeit in response to formal assessments.

\section{Flow: Time and thresholds}

Although it is claimed that educational cyberspace facilitates anytime, anywhere learning, it should not be seen as a completely amorphous space. Rather it is subject to flows of time and people. Foucault (1986) noted that heterotopias are linked to slices of time, either accumulating it or unveiling its transitory nature. It was this latter quality upon which respondents commonly focused. With Facebook it was asserted that " 10 minutes lasts an hour. I just think I'll check one thing and then next thing I know I've been on there an hour not even realising” (Amrita). Hence time on Facebook was seen as transitory, but it also had the potential to extend required work periods through distraction:

[I]f I'm doing some work and I've got Facebook open then I get a message or I'll see pictures that my friend's posted from a party and I get distracted and I'll loose where I was in my work and then it's a bit like I've lost my place and it's hard to get back in and you know, all from that one little message. (Brent)

Insofar as Facebook functions as a distraction, it not only accentuates the transitory nature of the temporal, but also in effect hijacks time, making re-engagement with work more difficult. It is not just 
SNS that can foster such problems, as students are "sometimes supposed to be learning and you're like playing games and stuff like that” (Dylan). Yet, given Facebook's status as a higher education learning tool, it is important to recognise possible limitations. Despite the potential use of the Facebook timeline as a surveillance device to monitor an individual's contribution to collaborate projects, none of the respondents touched upon this issue. This might reflect the limited nature of the work undertaken on their group Facebook pages.

It is asserted that heterotopic sites are not freely accessible like public places, but presuppose a system of opening and closing. As Rymarczuk and Derksen (2014) argue, Facebook and other SNS, are not open systems insofar as they have thresholds and gatekeepers. Thus a user can only enter Facebook once they have identified themselves and registered. There may be even more stringent entry requirements for educational Facebook groups insofar as members limit entry to those in the same study cluster, course or degree. With smaller, assignment based SNS groups it is possible that ostracised students might be, or at least feel, symbolically excluded. Focusing on formal use of SNS in a postgraduate course, Ferreday and Hodgson (2010) touch upon the matter of online groups, spurning those who are perceived as not making an adequate contribution to the learning community. Although none of the respondents in this research suggested that this had happened, Gerald did express a sense of resentment and a desire to disengage arising from the activity of other people on Facebook. This suggests that flows can be influenced by underlying power dynamics.

\section{Conclusion}

It is vital to explore Facebook's spatial milieu in considering its role as a learning tool. Drawing upon Foucault's notion of heterotopia allows such analysis to be nuanced while reflecting social complexities. Although using SNS to deviate from the normal practice of teaching and learning in an educational setting may allow bursts of academic creativity and foster learning communities, such outcomes are not guaranteed. The educational heterotopian framework offers various insights into Facebook use, while raising questions about its effectiveness as a learning tool. In conclusion it is worth further reconsidering difference, notably in perceptions of work/play and underlying flows of power.

Key to encouraging effective education-related SNS use is the deconstruction of what constitutes useful academic work. Indeed Escobar-Rodriguez, Carvajal-Trujillo, \& Monge-Lozano (2014; p. 137) argue that "one of the barriers to the adoption of Facebook as a learning tool could be students' perceptions regarding technology use in personal space versus learning spaces”. This juxtaposition between work and social life is a common theme in studies exploring educational SNS use. In this research students had a distinct definition of what counted as study, primarily constructed around assessment requirements. Such notions may reflect dominant university discourses and "that educators tend to use SNS to support didactic teaching” (Rambe \& Ng'ambi, 2014; p. 323). Whilst students were often distracted by the social networking aspects of Facebook they clearly labelled this as play rather than study. Such a restrictive definition of work could prove problematic. Robinson (2009) argues that task orientated approaches to educational internet use result in a taste for the necessary, making it harder to develop sophisticated skills. In contrast, informal learning through playing seriously, a kind of enriching recreation, can result in advanced academic abilities as well as fostering soft skills (Hope, 2013). The development of such skills is increasingly important not only because they can facilitate broader critical understanding, but also because these are what employers increasingly want. As universities focus on desirable graduate attributes such as communication skills, self-awareness and emotional intelligence SNS use could become progressively important as an area for the development of such competences. In practical terms this means that notions of what actually constitutes productive work online needs to be challenged and reimagined. An overreliance on curriculum based competencies may prove stifling.

Such considerations also draw attention to underlying dynamics of power and resistance. Thus students also used Facebook to escape formal learning spaces, tuning out of classes, logging into social networks and engaging in acts of playful resistance (Hope, 2010). Consequently deviance that occurs in these different spaces may have more in common with avoiding boring lessons, than usurping traditional pedagogic forms to create new learning opportunities. Such notions highlight that power relations are not necessarily unidirectional. Rather students respond in various ways to educators' expectations that they participate formally in course-related Facebook use, including (feigned) compliance, lurking, resistance and non-participation (Rambe \& Ng'ambi, 2014). Whilst critiquing notions of work/play may lead to a 
relabelling of some activities, it is likely that much unproductive online activity will continue. The discussion of heterotopian cyberspaces suggests that not all of this will be intentional. Indeed students drew attention to the problem of wasting "wasting time" on Facebook as they grew distracted and time became transitory. This concern with the transient nature of time suggests that in addition to drawing on theories of space to explore the educational use of social networking sites, there is also a need for a temporal focus. Sociological work highlighting the pervasive, socially constructed role of time in society may be helpful in pursuing this line of study (Adams, 1994, 2013). Fundamentally this suggests that education-related SNS use is always going to have practical limitations.

In the universities of the future mobile learning and ambient computing environments will become increasingly important. This will impact on how such institutions function and the ways in which their spaces are (re)constituted. As SNS use is widespread and educational institutions can cheaply appropriate such technologies for their own ends, it is highly likely that sites such as Facebook will form part of this ambient architecture. Consequently, it is vital that practitioners and researchers consider the spatial dynamics of SNS and how these will impact on students' learning experiences. Drawing upon Foucault's notion of heterotopia it has been argued that such cyberspaces should be understood as different spaces, counter-sites. This suggests that treating them in the same way as traditional teaching places may create difficulties, while failing to realise their potential as tools for learning in the broadest sense. Ultimately, if universities are to be architects of the future, rather than its victims, the inherent differences of such learning spaces need to be recognised and traditional notions of academic work challenged. Educational heterotopia could provide a useful, critical tool in this process.

\section{Acknowledgements}

The research reported in this article was part of the project Net Generation encountering e-learning at university funded by the UK Economic and Social Research Council (Grant RES-062-23-0971). The author is grateful to the research team for inclusion in part of the data collection process and permission to use the resultant material.

\section{References}

Adam, B. (1994). Time and social theory. Cambridge: Polity Press.

Adam, B. (2013). Timewatch: The social analysis of time. Cambridge: Polity Press.

Aydin, S. (2012). A review of research on Facebook as an educational environment. Educational Technology Research and Development, 60(6), 1093-1106. doi: 10.1007/s11423-012-9260-7

Beyes, T., \& Michels, C. (2011). The production of educational space: Heterotopia and the business university. Management Learning, 42(5), 521-536. doi:10.1177/1350507611400001

Blair, E. (2009). A further education college as a heterotopia. Research in Post-Compulsory Education, 14(1), 93-101. doi:10.1080/13596740902717465

Bosch, T. E. (2009). Using online social networking for teaching and learning: Facebook use at the University of Cape town. Communication: South African Journal for Communication Theory and Research, 35(2), 185-200. doi:10.1080/02500160903250648

Cohen, J. (2007). Cyberspace as/and space. Columbia Law Review, 107(1), 210-256. Retrieved from http://papers.ssrn.com/sol3/papers.cfm?abstract_id=898260

Crouch, M., \& McKenzie, H. (2006). The logic of small samples in interview based qualitative research. Social Science Information, 45(4), 483-499. doi:10.1177/0539018406069584

Escobar-Rodriguez, T., Carvajal-Trujillo, E., \& Monge-Lozano, P. (2014). Factors that influence the perceived advantages and relevance of Facebook as a learning tool: An extension of the UTAUT. Australasian Journal of Educational Technology, 30(2), 136-151. Retrieved from http://ajet.org.au/index.php/AJET/article/view/585/932

Facebook (2014). Form 10-K annual report. Retrieved from http://investor.fb.com/secfiling.cfm?filingid=1326801-14-7\&CIK=1326801

Ferreday, D., \& Hodgson, V. (2010). Heterotopia in networked learning: Beyond the shadow side of participation in learning communities. Lancaster University: The Department of Management Learning and Leadership, (Management Learning and Leadership Working Paper Series). Retrieved from http://eprints.lancs.ac.uk/49033/1/Document.pdf

Foucault, M. (1970). The order of things. Andover: Tavistock.

Foucault, M. (1986). Of other spaces. Diacritics 16(1), 22-7. doi:10.2307/464648 
Foucault, M. (1998). Different spaces. In J. D. Faubion (Ed.), Aesthetics, method, and epistemology: Essential works of Foucault, (Vol. 2, pp. 175-185). London: Penguin.

Foucault, M. (2008). Of other spaces. In M. Dehaene, \& L. De Cauter (Eds.), Heterotopia and the city (pp. 13-30). London: Routledge.

Genocchio, B. (1995). Discourse, discontinuity, difference: the question of other spaces. In S. Watson, \& K. Gibson (Eds.), Postmodern cities and spaces (pp. 35-46). Oxford: Blackwell.

Gulson, K., \& Symes, C. (2007). Knowing one’s place: Space, theory, education. Critical Studies in Education, 50(1), 93-102. doi:10.1080/17508480601123750

Haider, J., \& Sundin, O. (2009). Beyond the legacy of the enlightenment? Online encyclopaedias as digital heterotopias. First Monday, 15(1). doi.org/10.5210/fm.v15i1.2744

Hamid, S., Waycott, J., Kurnia, S., \& Chang, S (2014). An empirical study of lecturers' appropriation of social technologies for higher education. Australasian Journal of Educational Technology, 30(3), 295311. Retrieved from http://ajet.org.au/index.php/AJET/article/view/690/987

Hope, A. (2010) Student resistance to the surveillance curriculum. International Studies in Sociology of Education, 20(4), 319-334. doi:10.1080/09620214.2010.530857

Hope, A. (2013). The shackled school internet: Zemiological solutions to the problem of over-blocking. Learning, Media and Technology, 38(3), 270-283. doi:10.1080/17439884.2012.670646

Hung, H., \& Yuen, S. (2010). Educational use of social networking technology in higher education. Teaching in Higher Education, 15(6), 703-714. doi:10.1080/13562517.2010.507307

Ingrey, J. (2013). The public school washroom as heterotopia: Gendered spatiality and subjectification. (Doctoral dissertation). University of Western Ontario Retrieved from http://ir.lib.uwo.ca/etd/1768

Irwin, C., Ball, L., Desbrow, B., \&Leveritt, M. (2012). Students’ perceptions of using Facebook as an interactive learning resource at university. Australasian Journal of Educational Technology, 28(7), 1221-1232. Retrieved from http://www98.griffith.edu.au/dspace/bitstream/handle/10072/47627/80566_1.pdf?sequence=1

Johnson, P. (2006) Unravelling Foucault’s ‘different spaces’. History of the Human Sciences, 19(4), 7590. doi:10.1177/0952695106069669.

Johnson, P. (2013). The geographies of heterotopia. Geography Compass, 7(11), 790-803. doi:10.1111/gec3.12079

Junco, R. (2012). The relationship between frequency of Facebook use, participation in Facebook activities, and student engagement. Computers \& Education, 58(1), 162-171. doi:10.1016/j.compedu.2011.08.004

Kirschner, P. A., \& Karpinski, A. C. (2010). Facebook and academic performance. Computers in Human Behavior, 26(6), 1237-1245. doi:10.1016/j.chb.2010.03.024

Krikonis, M., \& Valsiner, J. (2008). The instant of being everywhere: Options and obstacles in technology-mediated education. Qwerty: Rivista italiana di tecnologia culture e formazione, 3(2), 6572. Retrieved from http://www.ckbg.org/qwerty/index.php/qwerty/article/view/32/31

Kozlovsky, R. (2010). The architecture of educare: motion and emotion in postwar educational spaces. History of Education, 39(6), 695-712. doi:10.1080/0046760X.2010.514295

Leaver, K., \& Kent, M. (2014). Introduction - Facebook in education: Lessons learnt. Digital Culture \& Education, 6(1), 60-65. Retrieved from http://www.digitalcultureandeducation.com/cms/wpcontent/uploads/2014/05/leaver.pdf

Madge, C., Meek, J., Wellens, J., \& Hooley, T. (2009). Facebook, social integration and informal learning at university: 'It is more for socialising and talking to friends about work than for actually doing work’. Learning, Media \& Technology, 34(2), 141-155. doi:10.1080/17439880902923606

Mason, R. (2006). Learning technologies for adult continuing education. Studies in Continuing Education, 28(2), 121-133. doi:10.1080/01580370600751039

Massey, D. (1999). Spaces of politics. In D. Massey, J. Allen, \& P. Sarre (Eds.), Human geography today (pp. 279-294). Cambridge: Polity Press.

McRae, L. (2014). Learning or liking: Educational architecture and the efficacy of attention. Digital Culture \& Education, 6(1), 30-46. Retrieved from http://www.digitalcultureandeducation.com/cms/wp-content/uploads/2014/05/mcrae.pdf

Rambe, P., \& Ng'ambi, D. (2014). Learning with and from Facebook: Uncovering power asymmetries in educational interactions. Australasian Journal of Educational Technology, 30(3), 312- 325. Retrieved from http://ajet.org.au/index.php/AJET/article/view/116/988

Robinson, L. (2009). A taste for the necessary: A Bourdieuian approach to digital inequality. Information, Communication and Society, 12(4), 488-507. doi:10.1080/13691180902857678 
Roblyer, M. D., McDaniel, M., Webb, M., Herman, J., \& Witty, J. V. (2010). Findings on Facebook in higher education: A comparison of college faculty and student uses and perceptions of social networking sites. The Internet and Higher Education, 13(3), 134-140. doi:10.1016/j.iheduc.2010.03.002

Rosenfeld, E. (2015). Facebook quarterly results beat on most metrics. CNBC. Retrieved from http://www.cnbc.com/2015/07/29/facebook-earnings-50-cents-per-share-vs-expected-eps-of-47cents.html

Ryan, G.W., \& Bernard, H. R. (2003). Techniques to identify themes. Field Methods, 15(1), 85-109. doi:10.1177/1525822X02239569

Rymarczuk, R., \& Derksen, M. (2014), Different spaces: Exploring Facebook as heterotopia. First Monday, 19(6). doi.org/10.5210/fm.v19i6.5006

Selwyn, N. (2009). Faceworking: Exploring students' education-related use of Facebook. Learning, Media and Technology, 34(2), 157-174. doi:10.1080/17439880902923622

Staines, Z., \& Lauchs, M. (2013). Students' engagement with Facebook in a university undergraduate policing unit. Australasian Journal of Educational Technology, 29(6), 792-805. Retrieved from http://ajet.org.au/index.php/AJET/article/viewFile/270/776

Stutzman, F. (2008). The vibrancy of online social space. In B. Rigby (Ed.), Mobilizing generation 2.0: A practical guide to using web 2.0 technologies to recruit, engage \& activate youth (pp. 95-96). New York, NY: Jossey-Bass.

Tamboukou, M. (2004). Educational heterotopias and the self. Pedagogy, Culture \& Society, 12(3), 399413. doi:10.1080/14681360400200209

Warschauer, M. (1995). Comparing face-to-face and electronic discussion in the second language classroom. CALICO Journal, 13(2/3), 7-26. Retrieved from https://www.calico.org/html/article_604.pdf

Willis, J., Spiers, L., \& Gettings, P. (2013). MOOCs and Foucault's heterotopia: On community and selfefficacy. Paper presented at the Sixth International Conference of MIT's Learning International Networks Consortium (LINC), Cambridge, Massachusetts. Retrieved from http://linc.mit.edu/linc2013/proceedings/Session3/Session3Willis.pdf

Vivian, R. (2011). University students’ informal learning practices using Facebook: Help or hindrance? Communications in Computer and Information Science, 177(1), 254-267. doi:10.1007/978-3-64222383-9_21

Young, S. (1998). Of cyber spaces: The Internet \& heterotopias. M/C Journal, 1(4). Retrieved from http://journal.media-culture.org.au/9811/hetero.php

Corresponding author: Andrew Hope, andrew.hope@adelaide.edu.au

Australasian Journal of Educational Technology (c) 2016.

Please cite as: Hope, A. (2016). Educational heterotopia and students' use of Facebook. Australasian Journal of Educational Technology, 32(1), 47-58. 